УдК 930.1

\title{
Л.А. Гаман
}

\section{РУССКАЯ РЕВОЛЮЦИЯ 1917 Г. И МОДЕРНИЗАЦИЯ: Н.А. БЕРДЯЕВ О НЕКОТОРЫХ АСПЕКТАХ РЕВОЛЮЦИИ В РОССИИ}

\begin{abstract}
Рассматриваются отдельные аспекты концепции Н.А. Бердяева (1874-1948 гг.) Русской революции 1917 г. Анализируются особенности его исследовательской стратегии, междисциплинарной по своему характеру. Освещаются его представления о некоторых предпосылках, характере и последствиях революции, о факторах, обусловивших ее своеобразие. Рассматриваются теоретические положения Бердяева о советской модернизации. Подчеркивается его стремление учитывать трагический характер и неоднозначность ее последствий.

Ключевые слова: революция; марксизм; менталитет; русская православная церковь; советская модернизация; советский неогуманизм.
\end{abstract}

Русская революция 1917 г. как одно из ключевых событий XX в., повлекшая за собой глубинные трансформации в России, оказавшая продолжительное многоплановое влияние на систему международных отношений, в немалой степени определившая основные тенденции мирового развития в XX-XXI вв., продолжает вызывать научные и общественные дискуссии, обострившиеся в год ее 100-летия. Учитывая большую сложность этого события и необходимость формирования взвешенных его оценок, представляется важным обращение к идейно-теоретическому наследию русских эмигрантских авторов, таких как Н.А. Бердяев, Ф.А. Степун, Г.П. Федотов, И.А. Ильин и др., предложивших объяснительные версии революции в России, содержащие богатый фактографический и теоретико-методологический материал, способствующие углубленному ее исследованию.

В рамках данной работы рассматриваются некоторые аспекты историко-религиозной концепции Русской революции Н.А. Бердяева (1874-1948 гг.), посвятившего значительную часть своего творчества ее изучению. Не случайно в западном культурном сообществе он известен как компетентный историк Русской революции. Примечательно, что во Франции его книга «Истоки и смысл русского коммунизма» (1937 г.) выдержала восемь изданий и является классической для изучения этого периода российской истории [1. С. 154]. В качестве источников данной работы выступают произведения Бердяева, написанные им в поздний период творчества, преимущественно в 1930-1940-е гг. Важным источником являются труды некоторых его современников, главным образом Ф.А. Степуна, также посвятившего всестороннему исследованию революции значительную часть своих работ. Историко-философские построения Бердяева неизменно вызывали и продолжают вызывать интерес исследователей вплоть до настоящего времени [2-6]. Автором данной статьи также уделялось внимание изучению его концепции Русской революции 1917 г. и советской истории [7. С. 23-129; 8].

Предваряя дальнейшее изложение, необходимо охарактеризовать в общих чертах исследовательский метод Н.А. Бердяева, опираясь на который он предложил свою версию Русской революции. Будучи человеком христианского сознания, одним из ярких представителей религиозного символизма [4. С. 112$220]$, он подчеркивал свою приверженность «историо- софической точке зрения» на революцию, по его мнению, более других способствовавшей выявлению структурной сложности данного события [9. С. 106]. Историософский метод познания, междисциплинарный по своей сути, предполагал широкое обращение к достижениям социальных и гуманитарных наук, в особенности исторической науки, при непременном признании религиозных оснований исторического процесса. Своеобразие этого исследовательского метода определялось сложной комбинацией собственно научных подходов с основными постулатами христианской философии истории, что позволяло Бердяеву расширять проблематику, выявлять антропологическое измерение истории, находить разноплановые смысловые уровни макро- и микроисторических процессов и событий. Характерное для мыслителя стремление учитывать многофакторность исторического развития, значение в нем антропологической составляющей делает его работы, несмотря на дискуссионность многих его выводов, актуальными, созвучными научным поискам современной историографии [10. С. 5-25].

Историософский метод стал основой для анализа революции как важного события христианского периода истории в режиме «долгого времени» в широкой исторической перспективе в свете проблемы направленности исторического развития. Положение о принадлежности Русской революции 1917 г. христианскому периоду истории стало одним из фундаментальных для бердяевских размышлений о ее предпосылках, характере, ближайших и отдаленных последствиях и перспективах. Избранный ракурс позволил Бердяеву настаивать на всемирном - «вселенском» - значении Октябрьской революции как события, с невероятной силой актуализировавшего в новых исторических условиях христианский проект переустройства мира на более справедливых основаниях

С христианскими убеждениями было связано свойственное мыслителю отрицательное отношение к современной капиталистической системе, отличительной чертой которой, по его убеждению, стала тотальная дегуманизация человека. В исторической перспективе ее альтернативой должно было стать «трудовое общество» как социальная проекция «персоналистического социализма», способного гармонизировать проблему личности и общества, контуры которого Бердяев находил в пореволюционной России. В этой связи он писал в своей последней работе: 
«Западу следовало бы помнить, что Россия страшными жертвами спасла Европу от рабства, и что русский народ первый сделал социальный опыт, необычайный по смелости, и поставил новую тему для мира» [11. С. 279]. Одним из ключевых завоеваний революции он считал отмену эксплуатации человека человеком.

В искомом завещанном христианством преображении мира на религиозно-духовных основаниях, в построении более справедливого общества лидирующую роль Бердяев отводил России, Советской России как одному из модусов существования России вечной. «Когда я говорю “Россия”, - пояснял он, - я имею в виду не только советскую, пореволюционную Россию, но и Россию вечную» [12. С. 311]. Этот свой вывод он отстаивал до конца жизни, независимо от неприятия его значительной частью российской эмиграции, независимо от обвинений самого мыслителя в «просоветской ориентации». Его особенную горечь вызывало непонимание его позиции по отношению к Советской России единомышленниками по «пореволюционному сознанию», в частности Т.П. Федотовым, резко критиковавшим «просоветские» бердяевские взгляды в своих работах американского периода творчества (1942-1951 гг.) [2, 3]. В этой связи Бердяев писал в одном из писем: «Некоторые находят, что моя ориентация слишком советско-патриотическая. Меня очень огорчили дошедшие до меня сведения, что Георгий Петрович (Федотов. - Л.Г.) настроен совсем иначе, что его ориентация недостаточно русская...» [13. С. 217-218].

Особо подчеркнем, что Бердяев рассматривал «Февраль» и «Октябрь», как стадии единого революционного процесса, сближаясь в этой своей оценке с некоторыми другими сторонниками «пореволюционного сознания», например Ф.А. Степуном [14. С. 311]. «Русская революция, - отмечал Бердяев в одном из своих докладов, - отразила в себе сначала борьбу “общественности” с “государственностью” и минутную победу общественности (Февральская революция. - Л.Г.), затем всеобщий народный бунт против обеих борющихся сторон культурного слоя: и “государственности”, и “общественности”» [15. Л. 6]. В поздний период творчества мыслитель более всего писал о значении Октябрьской революции в связи с социальным переустройством мира, касаясь Февральской революции лишь вскользь. Несмотря на признание им этой последней «свободолюбивой» по своему характеру [16. С. 212], он подчеркивал ее бесперспективность, обусловленную чуждостью либеральнодемократических ценностей и принципов основной части русского народа.

Отдаленной причиной трагического взаимонепонимания передовой либерально настроенной общественности и народа, отчетливо проявившегося в ходе Октябрьской революции, не пощадившей культурную элиту, как и представителей революционной интеллигенции, Бердяев считал порожденный петровской модернизацией культурный раскол. Констатируя этот факт, он писал: «Оторванность культурного слоя от народа нашла свою законченность в Октябрьской революции 1917 г.». Чрезвычайно важным для понимания «срыва» Февраля является указание мыслителя на значение культурного раскола внутри самого культурного слоя России, оказавшегося неспособным к конструктивному консенсусу на начальной стадии революции. Он подчеркивал: «Слабая сплоченность культурного слоя породила в нем самом (культурном слое. - Л.Г.) раскол, который нашел свою законченность в февральской революции 1917 года» [15. Л. 5-6].

Однако основную причину низкой влиятельности либерализма в России Бердяев связывал с рядом особенностей российского менталитета, для которого, по его мнению, оказались мало свойственными «римские представления о собственности», «инстинкт буржуазной обеспеченности», «буржуазные добродетели», что в своей совокупности обусловило специфику коммуникационного пространства России, неблагоприятного для рецепции идей либерализма. В этой связи он писал: «...русским свойственны были буржуазные пороки, но не свойственны были буржуазные добродетели, как людям Запада. И это характерная черта. При таких свойствах в России не могло создаться сильной, уверенной в своей правоте буржуазии, не могло обнаружиться влиятельной буржуазной идеологии» [12. С. 178]. Особо отметим, что в свете рассматриваемой проблемы меньшую, в сравнении с европейцами, склонность русского народа к буржуазности Бердяев связывал с рядом его исторически воспитанных православным христианством свойств, прежде всего, «особого рода тоталитаризмом, т.е. стремлением к цельности, к тотальному преображению жизни, но и эсхатологизмом, т.е. устремлением к концу» [Там же. С. 316]. Признаем, что это едва ли в полной мере соответствует историческим реалиям, на что обращали внимание уже современники Н.А. Бердяева, например М.М. Карпович, глубокий знаток русской общественно-политической мысли, один из основоположников русистики в США. Убедительными контраргументами для ученого выступало положительное отношение советского народа к НЭПу, равно как широкое применение насильственных методов по отношению к русскому крестьянству в годы коллективизации [17. С. 283].

Важнейшим достижением Октябрьской революции Бердяев считал привлечение к исторической активности широких народных масс, что, согласно его убеждению, выгодно отличало ее от петровской модернизации, как известно, также обусловившей радикальные трансформации российского общества [9. C. 12-13]. Самостоятельное значение в его концепции революции занимает анализ русского коммунизма, представлявшего собой, по его мнению, «русифицированный марксизм», приспособленный к российским реалиям, оперируя идеями которого большевики сумели завоевать социальное доверие масс, получить их поддержку и «переключить» их религиозную энергию на строительство нового общества. Мыслитель, в частности, объективно показал, что переопределение роли крестьянства в революции, превращение его в «революционный класс» [Там же. С. 89] вразрез с классическим марксизмом позволило не только обеспечить социальную базу большевикам в стране с малой численностью пролетариата, но и запустить революционные процессы в странах «догоняющей модер- 
низации», что в перспективе стало основой создания «восточного блока». Он писал в этой связи: «Русификация марксизма привела к тому выводу, что коммунистическая революция должна происходить вопреки Марксу не в индустриализированных странах с сильным пролетариатом, а в странах отсталых, аграрных, с подавляющим преобладанием крестьянства. Это одна из причин образования восточного блока» [11. С. 274].

Значительное место в концепции Бердяева Русской революции 1917 г. занимает системный анализ ее предпосылок и причин. В данной работе коснемся лишь его интерпретации роли исторического православия в структуре причин революции. В своих работах 1930-1940-х гг. он подверг резкой критике «цезарепапизм», сакрализацию светской власти, чрезмерную зависимость исторического православия от государства, его слабую социально-преобразующую роль, низкий культурный уровень духовенства, что в своем сложном взаимодействии способствовало ослаблению христианской жизни в народе, снижению авторитета церкви и формированию в общественном сознании ее имиджа как силы реакционной, препятствующей модернизации страны. Резко критикуя историческое христианство, он писал: «Христиане страшно запаздывают, инициатива выпала из их рук. Лишь в средние века она была в их руках. В века же новой истории христиане проявили самый бессовестный конформизм, освящая любую неправду...» [18. С. 50]. Сходной позиции придерживался Степун, особенно сожалевший о том, что русская православная церковь не выработала своего учения об обществе, не взяла под свою защиту учение о естественных правах человека, как то было сделано католичеством. В результате, резюмировал мыслитель, учение о естественном праве «появляется в России не как христианская, а как антихристианская и, во всяком случае, как антицерковная тема» [19. С. 284-285].

Наряду с обоснованной критикой исторического православия оба мыслителя неизменно подчеркивали его большую положительную роль в российской истории. Специальное внимание ими было уделено роли русской православной церкви в формировании целого ряда особенностей российского менталитета, как положительных, так и негативных, в своем диалектическом единстве обусловивших разноплановые проявления социального поведения россиян во время революции и пореволюционного строительства. Так, поразившие мир необыкновенная жертвенность, социальный идеализм, энтузиазм русского народа в годы революции и Второй мировой войны, в период советского строительства мыслитель связывал с древними духовными источниками, с «духовным капиталом, приобретенным тысячелетним его христианским воспитанием» [12. С. 228].

Сущностной чертой историко-религиозных представлений Бердяева о Русской революции является восприятие ее как события, одновременно универсального, отмеченного типологическими чертами любой революции как формы социальной динамики, и уникального, самобытного, обусловленного эндогенными факторами развития. В этой связи уместно обратить внимание на значение проблем преемственно- сти и разрывов, традиции и новации в его историкотеоретических построениях. Для него было очевидно их диалектическое единство в историческом развитии, особенно с учетом онтологического измерения истории: «Одно сохранение прошлого есть претензия оторвать прошлое от господства над ним духа вечности, один соблазн творчества есть претензия оторвать будущее от господства над ним вечности» [20. С. 113]. «Власть прошлого», полагал мыслитель, в своих отрицательных и положительных проявлениях неизбежно влияла на развитие общества. В частности, характерный для советской системы этатизм он рассматривал как часть российской традиции деспотической власти, исторически мало считавшейся с интересами и социальными ожиданиями общественности. Подобно тому, как это было характерно для российской монархической политической системы, настаивал он, в СССР «интересы народа приносятся в жертву мощи и организованности советского государства» [9. C. 9].

Положение о преемственном характере деспотической власти в России представлялось дискуссионным многим современникам Бердяева. Так, Степун настойчиво подчеркивал коренную несхожесть российского монархического и советского политических режимов, настаивая на их разнородности. В качестве основного критерия, не позволяющего включать их в единую традицию российской власти, Степун считал отношение носителей власти к творимому ими в стране насилию. Формулируя ключевое отличие монархического и большевистского политических режимов, он писал: «Разница эта заключается в том, что монархию, исповедовавшую православие, и можно, и должно упрекать в содеянных ею тяжелых грехах, так как грех - основная категория христианского сознания. Упрекать же большевизм за греховность его убеждений и действий - бессмысленно, так как последовательное материалистическое сознание не знает понятия греха» [19. С. 339]. Роковым следствием этого стало широкое распространение насилия и имморализма в пореволюционной России, что нашло свое выражение не только в массовом терроре, но и в широком распространении шпионажа, доносительства, различных форм конформизма.

Сильной стороной концепции Бердяева является стремление учитывать роль международных факторов в историческом развитии, что приобретало дополнительное значение в условиях усиления интеграционных (глобализационных) процессов в мире, ускоренных двумя мировыми войнами XX в. Уже в 1914 г. в работе «Конец Европы» мыслитель писал об утрате Европой статуса монополиста культуры и неизбежности формирования в новых исторических условиях единой «мировой культуры». В этом ракурсе разворачивались его размышления не только о неизбежности (закономерности), но и о запоздалости революции в России. Едва ли не главным аргументом в пользу исчерпанности монархического политического режима в стране Бердяев считал его саморазложение в условиях неудачной войны, сопровождавшееся окончательной десакрализацией монархической идеи в общественном сознании народа [9. С. 110-111]. Так или 
иначе, падение российской монархии, по объективному мнению мыслителя, способствовало дальнейшей модернизации России, необходимой в условиях углубления международной интеграции. Подчеркивая неизбежность индустриального развития стран как ключевого условия решения «проблемы хлеба», повышения жизненного уровня численно растущего населения в мире, Бердяев настаивал на коренной необходимости российских модернизаций. Однако, по его убеждению, они со времен Петра Великого имели своей целью не только преодоление социальноэкономической и культурной отсталости страны, но и выполнение Россией исторической роли, которую он связывал, в соответствии со своей версией русской идеи, с реализацией социальной правды в мире. В свете этой мировой перспективы он положительно оценивал такие достижения советского государства, как прекращение «хаотического распада» России, вызванного революцией, и создание федеративной системы, что в результате позволило сохранить территориальную целостность страны и ее ресурсы, прежде всего человеческие ресурсы. «Создание советской федерации, - подчеркивал он, - объемлющей много племен и народов, было огромной заслугой» [12. С. 266]. В составе факторов, позволявших верить в великое будущее России, наряду с восстановлением территориальной целостности России, важными ему также представлялись жизнеспособность русской православной церкви, сохранившей свою организацию вопреки антицерковной политике советского государства, и высокая рождаемость в СССР, несмотря на «невыносимые экономические условия» в стране [15. Л. 8].

В своих работах 1930-1940-х гг., адресованных преимущественно западной аудитории, Бердяев стремился обосновать необходимость советской модернизации, в исторической перспективе обусловившей победу СССР над фашистской Германией. Специфику советской модернизации определяла приверженность коммунистической идеологии. Он считал объективно неизбежной форсированную - «острую» - индустриализацию страны, необходимую для преодоления промышленной отсталости России. Параллельная «американизация русских людей, выработка нового типа практика», их всеобщая увлеченность техникой вызывали определенные опасения Бердяева, полагавшего, что это может способствовать «обуржуазиванию» народа, тем не менее оценивались им положительно, равно как преодоление русской лени, «выработанной барством и крепостным правом» [9. С. 116]. При условии сохранения жертвенности и социального идеализма - свойств, воспитанных христианством, полагал он, эти компоненты трудовой этики могли способствовать строительству нового, более справедливого общества.

Полемизируя с западными оппонентами, находившими советскую модернизацию, вызванную революцией, чрезмерно жестокой, а советский народ варварским и обезличенным, Бердяев предлагал учитывать историческую специфику народа, отказаться от двойных стандартов в оценках европейской и российской моделей развития. Он обращал внимание на асинхронность модернизационных процессов в различных культурно-исторических регионах, на их неизбежно болезненный характер для любого сообщества на определенном этапе развития. В этой связи он писал: «В России происходит процесс острой индустриализации, процесс жестокий и мало считающийся с ценностями человеческой личности, как и многие процессы истории. [В России] индустриализация происходила под знаком коммунизма. В Англии начала XIX в. происходила под знаком индивидуалистического капитализма. Был ли процесс первоначального накопления в Англии... менее жесток и более человечен?» [12. С. 260]. Соглашаясь с Бердяевым в его стремлении объективно оценить значение и своеобразие советской модернизации, тем не менее следует признать, что он все-таки не ставил во всей остроте проблему цены советских достижений.

Бердяев высоко оценивал повышение культурного и образовательного уровня народа в пореволюционный период, несмотря на понижение качества культуры как таковой в Советской России, что он рассматривал как временное явление. Резюмируя культурные достижения советской модернизации, он отмечал: «Огромные народные массы приобщились к просвещению и к элементарной цивилизации с сильным уклоном к технике. Но качественный уровень культуры очень понизился. Культурной элиты больше не существует» [21. Л. 14]. Несмотря на сложность и неоднозначность последствий советской модернизации, Бердяев одним из первых эмигрантских авторов сумел увидеть тенденции зарождения неогуманизма в СССР, ярким проявлением которого стало всенародное увлечение творчеством А.С. Пушкина, отличающегося свободолюбием и человечностью. Показательным для него также являлось широкое распространение в советской образовательной системе педагогических идей Л.Н. Толстого [12. С. 247]. Констатация очевидных симптомов советского неогуманизма, тем не менее, не означала игнорирования мыслителем трагических проявлений процессов дегуманизации в Советской России, связанных с подавлением личности и репрессированием любых проявлений свободы в стране. Объяснение этому последнему он находил, прежде всего, в свойственном марксизму моральном релятивизме, доведенном до крайности в его русифицированной версии. Бердяев отмечал: «Марксизм утверждает моральный релятивизм, моральная оценка меняется в зависимости от социальных классов. Происходит разрыв с традициями христианской и гуманистической морали» [Там же. С. 200]. Примечательно, что одним из главных условий развития подлинной свободы в Советской России он объективно считал преодоление ее международной изоляции, особенно опасной в условиях углубления международной интеграции.

Особо отметим, что Бердяев являлся убежденными сторонником сохранения социальных достижений революции, выработанной советским народом трудовой этики, социальной солидарности. Он выступал категорическим противником реставрации капиталистической системы в России, полагая, что это приведет к «срыву» модернизации, к трагическому обесце- 
ниванию всех понесенных в ходе революции и советского строительства жертв, к измене русского народа своей национальной идее построения справедливого общества. Не случайно он писал в одной из своих последних работ: «Мировая роль советской России связана, прежде всего, с социальным переустройством мира. Первый раз во всемирной истории в основу социального строя огромной страны положен принцип, не допускающий эксплуатации человека человеком» [12. С. 258]. Бердяев был глубоко убежден, что, несмотря на все отрицательные стороны советской системы - «ложь коммунизма», она была способна к постепенной трансформации и практическому во- площению «правды коммунизма» в интересах русского народа и мирового сообщества в целом.

Таким образом, оригинальная, сложная по своей структуре и содержательному наполнению концепция Русской революции 1917 г. Н.А. Бердяева, отличающаяся семантической сложностью, содержит в себе богатейший материал, изучение которого необходимо для углубленного ее постижения. Предложенная мыслителем объяснительная версия революции способствует углубленному пониманию трагического характера российской истории, сложной природы революции в России и пореволюционного строительства в ней.

\section{ЛИТЕРАТУРА}

1. Маркадэ Ж.К. Проникновение русской мысли во французскую среду: Н.А. Бердяев и Л. Шестов // Русская религиозная мысль ХХ века : сб. статей / под ред. Н.П. Полторацкого. Питсбург, 1975.

2. Федотов Г.П. Ответ Н.А. Бердяеву // Федотов Г.П. Собр. соч. : в 12 т. / прим. С.С. Бычкова. М. : Мартис, 2004. Т. 9 : Статьи американского периода. С. 194-210.

3. Федотов Г.П. Н.А. Бердяев - мыслитель // Федотов Г.П. Собр. соч. : в 12 т. / прим. С.С. Бычкова. М. : Мартис, 2004. Т. 9 : Статьи американского периода. С. 278-291.

4. Степун Ф.А. Мистическое мировидение. Пять образов русского символизма / пер. с нем. Г. Снежинской, Е. Крепак, Л. Маркевич. СПб. : Владимир Даль, 2012. 479 с.

5. Ермичев А.А. Три свободы Николая Бердяева // Ермичев А.А. Имена и сюжеты русской философии. СПб., 2014. С. $241-266$.

6. Волкогонова О.Д. Бердяев. М. : Молодая гвардия, 2010. 390 с.

7. Гаман Л.А. Революция 1917 г. и советская история в освещении русской религиозной эмигрантской мысли. Томск : Изд-во Том. ун-та, 2008. $332 \mathrm{c}$.

8. Гаман Л.А. Некоторые аспекты концепции советской истории Н.А. Бердяева // Вестник Томского государственного университета. 2008. T. 310. C. $65-71$.

9. Бердяев Н.А. Истоки и смысл русского коммунизма. М. : Наука, 1990. 224 с.

10. Могильницкий Б.Г. У истоков Томской историографической школы. А.И. Данилов и проблема преемственности в отечественной историко-теоретической мысли ХХ века // Методологические и историографические вопросы исторической науки. Томск : Изд-во Том. унта, 2007. $358 \mathrm{c.}$

11. Бердяев Н.А. Третий исход // Новый журнал. Нью-Йорк, 1953. № 32. С. 271-280.

12. Бердяев Н.А. На пороге новой эпохи : сб. статей // Бердяев Н.А. Истина и Откровение. Пролегомены к критике Откровения. СПб. : Издво РХГИ, 1997. С. 156-372.

13. Письма писателей (Бердяева, Мочульского, Горького, Есенина, Куприна) // Новый журнал. Нью-Йорк, 1969. Кн. 95. С. $216-231$.

14. Степун Ф.А. Бывшее и несбывшееся. СПб., 2000. 651 с.

15. Бердяев Н.А. Смысл исторического момента, переживаемого в настоящее время Россией : схема [доклада] (26 декабря 1934$)$ // РГАЛИ. Ф. 1496. Оп. 1. Ед. хр. 97.

16. Бердяев Н.А. Самопознание. М. : ДЭМ, 1990. 336 с.

17. Карпович М. Комментарии. В поисках «третьего исхода» (о статье Н.А. Бердяева) // Новый журнал. Нью-Йорк, 1953 . № 32 . С. $281-287$.

18. Бердяев Н.А. Христианство и революция // Новый град. 1937. № 12. С. 48-62.

19. Степун Ф.А. Чаемая Россия / сост. и послесл. А.А. Ермичева. СПб., 1999. 480 с.

20. Выдержки из писем Н.А. Бердяева Г.П. Федотову // Вестник Русского христианского движения. 1978. № 124. С. 117-120.

21. Бердяев Н.А. Трансформация марксизма в России (1940-е) // РГАЛИ. Ф. 1496. Оп. 1. Ед. хр. 263.

Статья представлена научной редакцией «История» 28 января 2018 г.

\section{RUSSIAN REVOLUTION OF 1917 AND MODERNIZATION: NIKOLAI BERDYAEV ON SOME ASPECTS OF THE} REVOLUTION IN RUSSIA

Vestnik Tomskogo gosudarstvennogo universiteta - Tomsk State University Journal, 2018, 429, 111-116.

DOI: $10.17223 / 15617793 / 429 / 13$

Lydia A. Gaman, Seversk Institute of Technology, Branch of National Research Nuclear University MEPhI (Moscow Engineering Physics Institute) (Seversk, Russian Federation). E-mail: GamanL@yandex.ru

Keywords: revolution; Marxism; mentality; Russian Orthodox Church; Soviet modernization; Soviet neohumanity.

The aim of the paper is to cover some aspects of Nikolai Berdyaev's (1874-1948) concept on the Russian revolution of 1917 in connection with the problem of Russian cultural modernization in the 20th century. The relevance of the appeal to this part of his ideological and theoretical heritage containing the richest material whose study is necessary for a profound understanding of the premises, character and ambiguous consequences of the revolution caused by a complex interaction of the international and endogenous factors of the development is emphasized. The peculiarities of Berdyaev's research strategy cross-disciplinary in character combining actually scientific methods of knowledge and basic provisions of religious symbolism connected with a Christian paradigm of history are considered. Heuristic opportunities of this approach allowed him to bring about the systematic sociocultural analysis of the Russian revolution of 1917, innovative for the time, to broaden the problem field of the research, to take into account many factors of the revolution and its polysemantic character. In particular, he was able to reveal the significance of historically formed people's mental features, both positive and negative, that affected in their dialectical interaction many peculiarities of the revolution and Soviet modernization caused by it. Special attention is paid to covering the mixed factor of the Russian Orthodox Church as part of the revolution reasons. Being a Christian thinker, Berdyaev considered this event in the light of a historical process problem. His aspiration to reveal negative and positive demonstrations and results of the Russian revolution of 1917 in their dialectic 
unity is emphasized to have been defined by his belief in the relation of this event to the Christian period of history. Berdyaev, like some other Russian thinkers, for example, Stepun, is noted to consider "February" and "October" as parts of an indivisible revolutionary process; he paid special attention to the October revolution and believed in its universal significance. Berdyaev's ideas of the Soviet modernization caused by the revolution, his connecting its specificity with the communistic ideology, are covered. In the conditions of the international integration deepening his aspiration to consider modernization inevitability in the world is noticed. Along with it, the importance of his theoretical provision on the asynchrony of social and cultural modernization of Russia and Europe that should be considered in the analysis of the Soviet modernization version is emphasized. Berdyaev's positive evaluation of social consequences of the revolution in Russia, above all, the abolition of man by man exploitation and the mission of the historical masses activity is particularly pointed out in the paper. At the same time the thinker is noted not to have put the value problem of the Soviet achievements as an acute one. A conclusion about the content, the relevance and scientific significance of Berdyaev's concept on the Russian revolution of 1917 is drawn.

\section{REFERENCES}

1. Marcadé, J.-C. (1975) Proniknovenie russkoy mysli vo frantsuzskuyu sredu: N.A. Berdyaev i L. Shestov [Penetration of Russian thought into the French environment: N.A. Berdyaev and L. Shestov]. Translated from French. In: Poltoratskiy, N.P. (ed.) Russkaya religioznaya mysl' XX veka [Russian religious thought of the 20th century]. Pittsburgh: University of Pittsburgh.

2. Fedotov, G.P. (2004) Sobr. soch.: v 12 t. [Works: in 12 vols]. Vol. 9. Moscow: Martis. pp. 194-210.

3. Fedotov, G.P. (2004) Sobr. soch.: v 12 t. [Works: in 12 vols]. Vol. 9. Moscow: Martis. pp. $278-291$.

4. Stepun, F.A. (2012) Misticheskoe mirovidenie. Pyat' obrazov russkogo simvolizma [Mystical Worldview. Five images of Russian symbolism]. Translated from German by G. Snezhinskaya, E. Krepak, L. Markevich. St. Petersburg: Vladimir Dal'.

5. Ermichev, A.A. (2014) Imena i syuzhety russkoy filosofii [Names and plots of Russian philosophy]. St. Petersburg: Nauka. pp. $241-266$.

6. Volkogonova, O.D. (2010) Berdyaev. Moscow: Molodaya gvardiya. (In Russian).

7. Gaman, L.A. (2008) Revolyutsiya 1917 g. i sovetskaya istoriya v osveshchenii russkoy religioznoy emigrantskoy mysli [Revolution of 1917 and Soviet history in covering Russian religious emigre thought]. Tomsk: Tomsk State University.

8. Gaman, L.A. (2008) Several aspects of N.A. Berdyaev's conception of soviet history. Vestnik Tomskogo gosudarstvennogo universiteta - Tomsk State University Journal. 310. pp. 65-71. (In Russian).

9. Berdyaev, N.A. (1990) Istoki i smysl russkogo kommunizma [The origins and meaning of Russian communism]. Moscow: Nauka.

10. Mogil'nitskiy, B.G. (2007) U istokov Tomskoy istoriograficheskoy shkoly. A.I. Danilov i problema preemstvennosti v otechestvennoy istorikoteoreticheskoy mysli XX veka [At the origins of the Tomsk historiography school. A.I. Danilov and the problem of continuity in the Russian historical and theoretical thought of the twentieth century]. In: Mogil'nitskiy, B. \& Nikolaeva, I.Yu. (eds) Metodologicheskie $i$ istoriograficheskie voprosy istoricheskoy nauki [Methodological and historiographical issues of historical science]. Tomsk: Tomsk State University.

11. Berdyaev, N.A. (1953) Tretiy iskhod [Third Exodus]. Novyy zhurnal - The New Review. 32. pp. 271-280.

12. Berdyaev, N.A. (1997) Istina i Otkrovenie. Prolegomeny k kritike Otkroveniya [Truth and Revelation. Prolegomena to the criticism of Revelation]. St. Petersburg: Izd-vo RkhGI. pp. 156-372.

13. Novyy zhurnal - The New Review. (1969) Pis'ma pisateley (Berdyaeva, Mochul'skogo, Gor'kogo, Esenina, Kuprina) [Letters from writers (Berdyaev, Mochulsky, Gorky, Yesenin, Kuprin)]. Novyy zhurnal-The New Review. 95. pp. $216-231$.

14. Stepun, F.A. (2000) Byvshee i nesbyvsheesya [The former and unfulfilled]. St. Petersburg: Aleteyya.

15. Russian State Archive of Literature and Art (RGALI). Fund 1496. List 1. Unit 97. Berdyaev, N.A. (1934) Smysl istoricheskogo momenta, perezhivaemogo $v$ nastoyashchee vremya Rossiey: skhema [doklada] (26 dekabrya 1934) [The meaning of the historical moment currently experienced by Russia: the scheme of [the report] (December 26, 1934)].

16. Berdyaev, N.A. (1990) Samopoznanie [Self-cognition]. Moscow: DEM.

17. Karpovich, M. (1953) Kommentarii. V poiskakh "tret'ego iskhoda" (o stat'e N.A. Berdyaeva) [Comments. In search of a "Third Exodus" (on the article by N.A. Berdyaev)]. Novyy zhurnal-The New Review. 32. pp. 281-287.

18. Berdyaev, N.A. (1937) Khristianstvo i revolyutsiya [Christianity and Revolution]. Novyy grad. 12. pp. 48-62.

19. Stepun, F.A. (1999) Chaemaya Rossiya [The desired Russia]. St. Petersburg: RKhGI.

20. Vestnik Russkogo khristianskogo dvizheniya. (1978) Vyderzhki iz pisem N.A. Berdyaeva G.P. Fedotovu [Excerpts from letters of N.A. Berdyaev to G.P. Fedotov]. Vestnik Russkogo khristianskogo dvizheniya. 124. pp. 117-120.

21. Russian State Archive of Literature and Art (RGALI). Fund 1496. List 1. Unit 263. Berdyaev, N.A. (1946) Transformatsiya marksizma v Rossii (1940-e) [Transformation of Marxism in Russia (1940s)]. 